\title{
COMPARTILHAR A MESA. DESIGN CENTRADO EM PESSOAS PARA RECURSOS MUSEOGRÁFICOS EDUCATIVOS
}

\section{Sharing the table. Human centered design as educational museographic resources}

Compartir la mesa. Diseño centrado en personas para recursos museográficos educativos

[Resenha do artigo de Nayeli Zepeda Arias publicado em DAT Journal, São Paulo, v. 5, n. 2, p. 129-139, 2020]

> Bruna L. Estevão da Silva [Universidade Anhembi Morumbi, Brasil] ${ }^{*}$

(Submetido: 28/1/2021;

Aceito: $13 / 5 / 2021$

Publicado: $7 / 7 / 2021$ )

Citação recomendada:

SILVÁ, Bruna L. Estevão

da. Compartilhar a

mesa. Design centrado

em pessoas para

recursos museográficos

interativos - Resenha.

Revista Poiésis,

Niterói, v. 22, n. 38

p. 345-349, jul./dez.

2021. [https://doi.

org/10.22409/poie-

sis.v22i38.48996]

Este documento é

distribuído nos termos

da licença Creative

Commons Atribuição

- NãoComercial 4.0

Internacional [CC-BY-

NC] (C) 2021 Bruna L.

Estevão da Silva

\section{RESUMO}

Resenha do artigo Compartir la mesa. Diseño centrado en personas para recursos museográficos educativos, de Nayeli Zepeda Arias, historiadora da arte, mestre em museografia interativa e didática e coordenadora do NodoCultura.

PALAVRAS-CHAVE design centrado nas pessoas, Design Thinking, recursos educacionais, visitantes, usuários, educação em museus

\section{ABSTRACT}

Review of the article Sharing the table. Human centered design as educational museographic resources, written by Nayeli Zepeda Arias, art historian, interactive and learning museology specialist and coordinator of NodoCultura. KEYWORDS human-centered design, Design Thinking, educational resources, visitors, users, museum education

\section{RESUMEN}

Revisión del artículo Compartir la mesa. Diseño centrado en personas para recursos museográficos educativos, escrito por Nayeli Zepeda Arias, historiadora del arte, experta en museología interactiva y coordinadora de NodoCultura. PALABRAS CLAVE diseño centrado en personas, Design Thinking, recursos educativos, visitantes, usuarios, educación en museos

*Bruna L. Estevão da Silva é mestranda em design pelo Programa de Pós-Graduação da Universidade Anhembi Morumbi. E-mail: estevao.bruna@yahoo.com.br. ORCID: https://orcid.org/0000-0002-2400-2284 
Historiadora de Arte pela Universidade Ibero-Americana e Mestre em Museografia Interativa e Didática pela Universidade de Barcelona, Nayeli Zepeda Arias colabora há mais de dez anos com instituições públicas e privadas no México e nos Estados Unidos. Além de coordenar o NodoCultura, coletivo multidisciplinar que explora práticas comuns e dissidentes em museus, integra o Museu Empathetic, iniciativa dedicada à construção de museus diversos, equitativos, acessíveis e inclusivos.

Neste artigo, a autora se refere ao museu como uma mesa, um lugar de comunhão, onde cada participante leva seu prato e todos compartilham a ceia, de modo que a mesa se torna o espaço onde se desenvolvem atividades sociais, comunitárias e também de pertencimento - é preciso enfatizar a importância do pertencimento, pois o visitante que não se sente pertencente à uma determinada comunidade ou espaço não demonstra interesse na preservação e participação das atividades ali exercidas. Logo de início, a autora afirma que a mesa está aberta e todos são bem-vindos e capazes de contribuir e apreender, de modo que é necessário reaprender com o visitante para, então, construir um novo museu. Ela afirma que as desigualdades socioeconômicas perdem a importância quando se compartilha a mesa dentro de um contexto cotidiano e as diferenças não restringem as formas de in- teração, mas evidenciam ainda mais tais trocas. $\bigcirc$ design centrado em pessoas é apresentado como uma estratégia para compartilhar a mesa com os visitantes e estabelecer processos colaborativos na construção do museu.

O museu do século XXI transcende as funções básicas de preservar, conservar, expor e pesquisar, e torna-se parte da dinâmica cultural das cidades. Dessa forma, estratégias como a curadoria educacional, a mediação e a integração de outras práticas, como o design centrado em pessoas, apresentam o museu como um local crítico, consciente, transparente e inclusivo, oferecendo ao visitante a oportunidade de experienciar e interagir com o espaço e os outros visitantes. Segundo a autora, compartilhar a mesa e criar relações democráticas dentro do museu é mais do que criar ferramentas que valorizam a participação do público. O design centrado em pessoas parte de uma abordagem empática e está ligado ao design participativo e co- design, que se baseia na investigação, no conhecimento profundo dos usuários e em suas formas de interagir e construir significado; esta abordagem está ligada ao design thinking, um processo crítico e criativo que possibilita a organização de ideias e a busca por conhecimento. No artigo, assim como na abordagem do design thinking, a autora divide o processo em quatro fases: inspiração, idealização, 
implementação e avaliação. Contudo, a definição dos problemas também é considerada como uma fase do design thinking.

Em Inspiração: empatia como hábito, a autora avalia que o design centrado em pessoas pode valer-se de estratégias como empatia, observação, monitoramento. A empatia no âmbito museológico esclarece os propósitos. Na inspiração, devemos percorrer os espaços por onde passam os visitantes e ouvi-los, para conhecer e aprender sobre suas dificuldades e diferenças, para, então, propor um projeto acessível.

A segunda fase do processo é intitulada como Idealização: o design como investigação, que se encarrega de interpretar e explicar as narrativas anteriormente encontradas, assim como contextualizar e estabelecer os caminhos para desenvolver os recursos museológicos e educativos. A fim de exemplificar, a autora discorre sobre um Sprint realizado no museu de Phoenix em 2016, no qual, em um dia, foi desenvolvido um guia impresso na tentativa de desmistificar a visita ao museu; foi perguntado por que as pessoas visitam os museus e porque tiram selfies. A resposta era para constar que eles estiveram ali. Como resultado, foram impressas duzentas cópias dos guias com a inscrição "I'm here" para fazer uma avaliação pública.
A terceira fase, Implementação: da ideia ao protótipo, a autora afirma que a elaboração e uso de protótipos é uma proposta de desenvolvimento museográfico iniciada nos museus de ciência. Os museus são incubadoras controladas onde se experienciam elementos museográfico, cujo o propósito é provar a relevância de ideias e projetos. Para demonstrar a implementação de protótipos, a autora apresenta dois exemplos que, através da experiência, basearam-se na participação do público: o Exploratorium de San Francisco [EUA, 1970] e o Papalote Museu del Nino [Cidade do México, 1992].

A última fase, Avaliação: Aprender Juntos, determina que avaliar os recursos museográficos educativos requer observação, escuta e, invariavelmente, empatia e, portanto, ação. A avaliação possibilita que a aprendizagem seja constante e dinâmica. A autora cita a reforma da galeria da história da Califórnia, no museu de Oakland, como um exemplo de avaliação. Os organizadores do museu convocaram um grupo formado por profissionais vinculados ao museu e visitantes assíduos para captar feedbacke comentários - por meio de protótipos, entrevistas, encontros de grupo e pesquisas - e foi implementado um programa específico para revisar esses recursos e diretrizes para seu desenvolvimento. 
Finalmente, a autora encerra o artigo afirmando que se queremos que as mudanças sejam duradoras e que a instituição museológica seja realmente relevante e social, é preciso partilhar a autoridade e dar ao visitante um espaço a mais à mesa, pois é na diversidade que somos capazes de aprender contribuir, reaprender, construir, e reconstruir a nós mesmos.

\section{CONSIDERAÇÕES}

O ideal de museu do século XXI não se encaixa mais nos padrões previamente estabelecidos. Os espaços museológicos vêm se tornando locais de aprendizagem, participação e convivência das cidades. Dado que os museus são espaços privilegiados de educação não formal e são importantes na formação de todos no campo da cultura, o espaço museológico se reafirma como intersecção entre os elementos de um triangulo - território, patrimônio e sociedade -, que culmina no diálogo entre diferentes camadas sociais, econômicas e políticas. O museu participativo se respalda em vínculos cognitivos e afetivos com o visitante, e sua transformação se dá a partir da empatia. Convidar o público a contribuir com a criação da narrativa do museu, ou como a autora coloca: dar um lugar à mesa, ratifica o processo de mudança, tornando-o um espaço mais inclusivo e plural. Contudo, deve haver intenção na mediação, é necessário conhecer profundamente o visitante, se colocar em seu lugar e não criar suposições. O design centrado em pessoas é uma abordagem que viabiliza a co-criação e a construção colaborativa da narrativa que, por sua vez, resulta em ações efetivas por parte do museu para tirá-lo do espectro de templo de elitismo cultural. Ao passo que se as necessidades do público mudam, o mesmo deve acontecer com os próprios museus.

O Museu da Imigração, localizado em São Paulo, é um exemplo de instituição brasileira que desenvolve iniciativas de mediação voltadas à empatia, aplicando a abordagem do design centrado em pessoas. A exposição permanente conta a história da imigração em São Paulo, por meio de objetos e depoimentos de pessoas vindas de todo o mundo. A exposição virtual "Viagem, sonho e destino" derivada de uma exposição itinerante - apresenta histórias sobre os imigrantes que contribuíram para formação de São Paulo. A exposição constrói sua narrativa a partir de registros fotográficos e relatos da população, apresentando o caminho destes imigrantes desde o porto de Santos até a Hospedaria de Imigrantes do Brás, com o objetivo de mostrar sua trajetória e o meio do caminho entre a vida que ficava para trás e a que estava por vir. < 
REFERÊNCIAS BIBLIOGRÁFICAS

ARIAS, Nayeli Z. Compartir la mesa. Diseño centrado en personas para recursos museográficos educativos. Dat Journal, v. 5, n. 2, p.129-139, 2020.

BIRKETT, Whitney B. To infinity and beyond: a critique of the aesthetic white cube. Submitted in partial fulfillment of the requirements for the degree of Master of Arts in Museum Professions. Seton Hall University, May 2012.

OLIVEIRA, G., O museu como um instrumento de reflexão social, MIDAS [online], 2|2013, posto online no dia 01 abril 2013, consultado dia 10/11/2020 URL: http://midas.revues.org/222; DOl: 10.4000/midas.222 Museu da Imigração. Disponível em: http://www.museudaimigracao.org.br/exposicoes/virtuais/viagem-sonho-e-destino. Acesso em 15/12/2020. 